\title{
Factors associated with length to recover adequate nutrition and length of stay in children hospitalized for bronchiolitis: a retrospective study.
}

\author{
Arnaud Maugendre ${ }^{1}$, Clément Médrinal $^{2}$, Tristan Bonnevie ${ }^{3}$, Pascal Le Roux ${ }^{2}$, Guillaume \\ Prieur $^{2}$, and Yann Combret ${ }^{2}$ \\ ${ }^{1}$ Cabinet COTTEAU et Assistant.e.s \\ ${ }^{2}$ Groupe Hospitalier du Havre \\ ${ }^{3}$ University Hospital Centre Rouen
}

February 19, 2022

\begin{abstract}
Context: Inadequate feeding is a frequent reason for hospital referring in children with bronchiolitis and leads to prolonged hospitalization in $26 \%$ of the cases. The main objective was to identify the factors associated with the time to recover adequate nutrition in infants hospitalized for bronchiolitis. Method: We conducted a single-center retrospective study including infants less than 12 months hospitalized for bronchiolitis at Le Havre Hospital (France) between September 2018 and February 2021. A multivariate logistic regression model was computed to investigate the factors associated with (1) the time to recover adequate feeding (LOFR), and (2) the hospital length of stay (LOS). Results: 268 infants were included to assess the LOFR and 478 infants to assess the LOS. The median age was 3.2 months (1.6-5.4) and the sex ratio M/F was 11/20. The use of accessory muscles, nutritional support, and $\mathrm{RR}$ [?] $70 / \mathrm{min}$ or $<30 / \mathrm{min}$ or apnea are associated ( $\mathrm{OR}=1.5)$, from virtually no association $(\mathrm{OR}=1.0)$ to a significant positive association $(\mathrm{OR}=2.6)$ with the LOFR. Intense use of accessory muscles $(\mathrm{OR}=3.9 ; 95 \% \mathrm{CI}$ 1.6-10.4) and "severe" clinical condition ( $\mathrm{OR}=2.8 ; 95 \% \mathrm{CI} 1.7-4.8)$ at admission, $\mathrm{O} 2$ supplementation $(\mathrm{OR}=2.0 ; 95 \% \mathrm{CI} 1.3-3.1)$ were significantly related to prolonged LOS in the multivariate analysis. Conclusion: The clinical severity on admission may be related to the LOFR, ranging from none to significant. Other known factors and the new clinical severity scale proposed by the latest French guidelines appeared to be related to the LOS in this work. Further studies are needed to highlight these factors.
\end{abstract}

\section{Introduction}

Bronchiolitis affects $30 \%$ of infants under 24 months of age ( $~ 480000$ children) every winter in France, with a low mortality rate (2.4-2.6 / 100000 births $)^{1,2,3}$. However, bronchiolitis leads to a high burden that importantly impacts the healthcare system every winter. Bronchiolitis is mostly mild and resolves spontaneously within a few days, but in France, 2 to $3 \%$ of the infants will have a severe form of the disease that require hospitalization. The average cost of hospitalization for the first episode of bronchiolitis is $5671 \backslash$ euro $( \pm 3354)$ and the average length of stay (LOS) is 3 days $( \pm 3)^{4}$. The latest international guidelines for in-hospital management of children with bronchiolitis recommend the use of sole supportive treatments: feeding and/or oxygen supplementation for infants who require it. The referral for airway clearance techniques (ACT) application is no longer recommended worldwide since no clear benefit have been reported ${ }^{3,5,6,7}$.

Several features have been linked with a higher LOS including a premature birth $<36$ weeks of gestational age (GA), and the presence of comorbidities ${ }^{5}$. Beyond these criteria, the nutrition is a determining factor 
in managing the LOS of these infants ${ }^{8,9}$. On the other hand, the factors associated with the time to recover adequate feeding (LOFR) are poorly known. Nonetheless, the latest French health authority guidelines $(\mathrm{HAS})^{5}$ proposed a new algorithm for hospital referring including feeding assessment further reinforcing the need to investigate the factors related with feeding in this population.

The main objective of this study was to investigate the factors associated with (1) the LOFR, and (2) the LOS. Among these factors, we aimed to investigate the indications for bronchiolitis ACT referring in our center.

\section{Methods}

\section{Ethics statement, study design and population}

We conducted a single-center retrospective study that was approved by our institutional ethics committee $\left(\mathrm{n}^{\circ} \mathrm{S} 21031211000\right)$ and has been declared to the Commission Nationale de l'Informatique et des Libertés (CNIL) (MR-004 $\mathrm{n}^{\circ}$ 2221599). According to the French law, formal consent was not required for this type of study. We included children aged $<12$ months hospitalized for bronchiolitis in Le Havre Hospital between September 2018 to February 2021. Non-inclusion criteria were: an age $>12$ months, a LOS $<24 \mathrm{~h}$ and multiple hospitalizations.

\section{Data collection and outcomes}

Children's characteristics were collected from our institution medical records (SILLAGE@ Medical and Care Information System software). The following reports were consulted, in order: the pediatric emergency report, the hospitalization report and the detailed care provided report. The data collected were as follows:

- Demographics: gender, age on admission, weight

- Comorbidities: prematurity (<36 GA), bronchopulmonary dysplasia, neuromuscular disease and congenital heart disease, chronic respiratory disease (childhood asthma), passive smoking, and a familial history of atopy (asthma, allergies).

- Parameters at the Emergency Department arrival (ED): time from onset of symptoms to hospitalization, heart rate and Silverman score $(/ 10)$, altered general condition (yes, no), feeding $(<$ or $>$ $50 \%$ of usual feeding), respiratory rate (RR), pulsed oxygen saturation $(\mathrm{SpO} 2 \%)$ in room air $(>92 \%$, $90 \%<\mathrm{SpO} 2 \%$ [?]92\%, [?] 90\% or cyanosis), and accessory muscle use (mild, moderate, or intense).

- Care during hospital stay: administration of bronchodilator and/or corticosteroid therapy, food support (nasogastric tube and/or intra veinous perfusion), oxygen support, use of ACT (at least every $48 \mathrm{~h}$ ), LOFR and LOS.

\section{Statistical analysis}

The clinical condition (severe, moderate, mild) as defined in the $\mathrm{HAS}^{5}$ was automatically calculated according to the extracted data, using an interface created to optimize the data collection process in Excel - Office $365(\mathrm{r})$ software (version 2004), and based on the aforementioned algorithm. For our main objective, adequate feeding was defined as a percentage of the daily amount of reconstituted milk $(\mathrm{mL})>70 \%$; on the basis of the Schofield equation and the latest European nutritional recommendations ${ }^{10,11}$. The daily amount of reconstituted milk $(\mathrm{mL})$ given to exclusively bottle-fed children was calculated on the basis of the modified Appert standard ${ }^{12}$. This calculation took the average growth curve values (weight and height by sex), the caloric values per $100 \mathrm{~mL}$ of reconstituted milk (first and second age) and the caloric adaptations for infants $<6$ months of age (E-Table 1 ). The LOFR was then defined as the time needed to reach a daily amount of feeding $>70 \%$ of this reference. The LOFR was only calculated for exclusively bottle-fed children, excluding 
breastfed (completely or partially) infants and those who had diversified feeding. However, the data collected for these infants were analyzable to investigate the factors associated with the LOS.

The usual procedure for ACT referred in our center is as follows: (1) a physician assesses the child and (2) refers to a specialist physiotherapist for ACT evaluation and (3) provide ACT or not regarding the clinical conditions of the child. The evaluation for ACT is repeated every day during hospital stay. For the present study, ACT referral (ACT+) was defined as the realization of an ACT session at least each 48h of hospitalization. A single evaluation was not rated as an ACT session. To distinguish the characteristics of the children that received ACT sessions during their hospital stay for bronchiolitis, the study sample was dichotomized according to whether at least one session of ACT was provided every 48 hours of hospital stay by a physiotherapist $(\mathrm{ACT}+)$ or not (ACT-).

Patients' characteristics are reported as numbers (and/or percentages) for categorical data; and as means (+- Standard Deviation (SD)) or median (InterQuartile Range (IQR)) for continuous data according to the distribution of the variables. The normality of the distribution for each variable was assessed using the Shapiro-Wilk test. For our main objectives, we calculated univariable logistic regressions for the dependent variables LOFR and LOS, including the patients' characteristics as independent variables. For this purpose, the LOFR was transformed into a binary variable between a short length $(<1$ day) and a prolonged length ([?] 1 day) based on the median LOFR of our population. Similarly, the LOS was also transformed into a binary variable between a short ( $<3$ days) and a prolonged ([?] 3 days) length, according to the average LOS for bronchiolitis in France ${ }^{13,14}$. A multivariate logistic regression model, using the dummy variable technique, was then calculated by including all the variables significantly associated (p[?]0.05) with each outcome, to isolate factors independently related to prolonged LOFR and LOS. Odds ratios (OR) and their Confidence Intervals $(95 \% \mathrm{CI})$ were reported.

The characteristics of the children that received ACT and those who did not were compared using the Mann-Whitney U test or Student's t test for continuous variables and the Fisher's exact test or the Chi2 test for categorical variables. A p-value [?]0.05 was considered as significant. All the statistical analyses were performed using GraphPad Prism $9^{(\mathrm{r})}$ software, version 9.0.1.

\section{Results}

\section{Study population}

From September 2018 to February 2021, 652 children were hospitalized with a diagnosis of bronchiolitis. Of them, 174 were not eligible for our study (Figure 1 ). A total of 268 children's reports were investigated for the predictive factors of the LOFR; and 478 were investigated for the LOS.

The median age of our sample was 3.2 months (1.6 - 5.4), 263 children were boys $(55.0 \%)$ and the median weight was $5.9 \mathrm{~kg}(4.5-7.2)$. Briefly, 94 children had a familial history of atopy (19.7\%) and 69 were born premature (14.4\%). The median LOFR was 1.0 days $(0.6-2.0)$ and the median LOS was 2.9 days (2.0 4.8). Table 1 presents the demographic and clinical characteristics of the patients, their comorbidities, the parameters at ED arrival and course of the stay (when available).

\section{Factors associated with the LoFR and the LOS}

In the univariate logistic regression model for LOFR: time delay between the first symptoms and the ED arrival (consultation time), RR [?] $70 / \mathrm{min}$ or $<30 / \mathrm{min}$ or apnea, moderate use of accessory muscles and nutritional support requirement were significantly associated with the LOFR (E-Table 2 ). In the multiple logistic regression model, none of the investigated associations reached statistical significance, but the estimate comes with uncertainty ranging from virtually no association to a significant positive association 
(95\% CI for the OR: 1.0 to 2.6) for the moderate use of accessory muscles, nutritional support and RR [?] $70 / \mathrm{min}$ or $<30 / \mathrm{min}$ or apnea that could be associated with the LOFR (Table 2 ).

In the univariate logistic regression model for LOS: age, weight, consultation time, severe clinical condition, $\mathrm{RR}$ [?] $70 / \mathrm{min}$ or $<30 / \mathrm{min}$ or apnea, $\mathrm{SpO} 2 \%<90 \%$ or cyanosis, intense use of accessory muscles, nutritional and oxygen support requirement were significantly associated with the LOS (E-Table 2 ). In the multiple logistic regression model, the intense use of accessory muscles $(\mathrm{OR}=3.9,95 \% \mathrm{CI} 1.6-10.4, \mathrm{p}=0.004)$, the severe clinical condition $(\mathrm{OR}=2.8,95 \% \mathrm{CI} 1.7-4.8, \mathrm{p}=0.001)$, and other known variables, such as the $\mathrm{O} 2$ supplementation $(\mathrm{OR}=2.0,95 \% \mathrm{CI} 1.3-3.1, \mathrm{p}=0.003)$ remained significantly associated with the LOS and the effect is large enough to be worthwhile (Table 2 ). For the consultation time (OR=1.2, 95\% CI 1.1 $1.3, \mathrm{p}=0.001)$ and the age $(\mathrm{OR}=0.8,95 \% \mathrm{CI} 0.7-0.9, \mathrm{p}<0.01)$, even if they remained significantly associated with the LOS, the effect may or may not be worthwhile.

\section{In-hospital referral for ACT}

Of the 478 infants included in our study, 299 (63\%) were referred for ACT during their hospital stay (ACT+). Children in the ACT+ group were significantly older (median age 2.6 (1.5-5.0) vs 3.5 (1.8-5.8) years; $\mathrm{p}=0.011$ ) and heavier (median weight $5.3(4.1-6.8)$ vs. $6.20(5.0-7.5) \mathrm{kg} ; \mathrm{p}<0.01)$ compared to those in the ACTgroup. Similarly, children in the ACT + group were less severe at admission and were more often prescribed bronchodilators but required less nutritional support. The complete characteristics of both groups are presented in theTable 3 .

\section{Discussion}

\section{Synthesis of the results}

The present study showed that (1) the moderate use of accessory muscles, nutritional support and RR [?] $70 / \mathrm{min}$ or $<30 / \mathrm{min}$ or apnea are associated $(\mathrm{OR}=1.5)$, from virtually no association $(\mathrm{OR}=1.0)$ to a significant positive association $(\mathrm{OR}=2.6)$ with the LOFR and (2) the new severity scale proposed the HAS and other known factors such as oxygen support appeared to be related to LOS in this work and (3) the $\mathrm{ACT}+$ group were older and heavier and had a less severe clinical condition at admission compared to the ACT- group.

\section{Adequate nutrition}

One major difficulty for this work was to define what constitutes adequate infant feeding. The current guidelines agree on the importance of maintaining adequate feeding during an episode of bronchiolitis, but a clear definition of the nutritional monitoring and management is lacking ${ }^{3,15}$. We chose to define adequate feeding according to the ratio of food intake to basal metabolic rate (BM), with a ratio [?]0.7 indicating adequate nutrition based on the latest Recommended Dietary Allowances (RDAs) of the French population and the European guidelines on parenteral nutrition ${ }^{11}$. Previous studies including children hospitalized for bronchiolitis in general ward and pediatric intensive care unit (PICU) proposed the use of different ratios (namely 0.8 and 0.9 ) to detect undernourished children based on expert committee ${ }^{16,17}$. Furthermore, the WHO recommends exclusive breastfeeding for children up to 6 months of age, and dietary diversification starts at about 6 months of age ${ }^{18,19,20}$. As these two forms of feeding are not suitable for mL measurement, we did not include 117 breastfed infants (24.4\%) and 93 who had started diversification (19.5\%), which could have impacted our results.

The HAS proposes to consider children with bronchiolitis feeding difficulties from a cut-off of $<50 \%$ of the habitual on three consecutive intakes ${ }^{5}$. According to this definition, almost all children who had feeding difficulties on admission received feeding support during the hospital stay (namely $31 \%$ and $28 \%$ ). This 
proportion is much lower than others studies $(86 \% \text { and } 82 \%)^{13,21}$ and could be explained by the higher objectivity of this cut-off value, compared to the oral parental reporting of feeding difficulties in these studies.

\section{Characteristics of the study sample}

The comorbidities previously identified as predictors of higher LOS are congenital heart disease with shunt, chronic pulmonary disease (such as cystic fibrosis), immune deficiency, neuromuscular disease (polyhandicap, Down syndrome), preterm birth ( $<36$ weeks of GA) and corrected age $<2$ months ${ }^{5,13,22}$. We did not find any association between them and prolonged LOS, possibly because they were not highly prevalent (1.4 to $3.5 \%)$, except for prematurity (14.4\%). Furthermore, compared to Gajdos et al. ${ }^{13}$, our lower proportions of infants exposed to parental smoking ( $7 \%$ vs. $27 \%$ ) or with atopic background ( $20 \%$ vs. $40 \%$ ) could be due to the absence of systematical reporting in the admission or medical records.

\section{Respiratory distress assessment}

The median Silverman-Anderson score was 2/10 at admission in the present study, corresponding to a mild respiratory distress. This could seem quite surprising for a cohort of hospitalized children and contradictory compared to the HAS severity scale, who mostly rated our cohort as moderate to severe bronchiolitis (39.9 and $51.8 \%$ respectively). These results can be explained by the important variability of symptoms during the beginning or the bronchiolitis course, called the critical period by Florin et al ${ }^{6}$. As most infants are hospitalized during the critical period, the clinical variability over 24 hours is important and may lead to inconsistencies in the clinical evaluation scores. Secondly, inter-observer reliability of the Silverman-Anderson score has been shown to be questionable between different caregivers ${ }^{23}$.

\section{The new severity scale (latest French guidelines)}

To our knowledge, this study is the first to investigate the relationship between this new severity scale proposed by the HAS and the hospitalization course of these children. It appeared that this scale was associated with the LOS in the present study, but could be questioning, especially since the median respiratory distress score was low. It is worth noting that the Silverman-Anderson score only rates the respiratory distress, whereas the severity scale includes more items, such as general condition and feeding. Secondly, it is usually advised to measure the infant's RR over a complete minute because of the variability of this parameter. However, in the context of a retrospective study, the RR could have also been rated according to the ED's monitor, which is usually higher and more variable, than the one-minute measure. In addition, assessing the general condition of a children is highly subjective, which could explain the discrepancies observed in the severity ratings. Finally, RR and HR are lower during sleep, which may influence the use of accessory muscles ${ }^{24}$. Unfortunately, the children state of arousal was not reported in the medical charts investigated.

\section{ACT}

In daily hospital practice, physiotherapists usually perceive the indication for ACT in the mildest infants with bronchiolitis. Several expert's opinion has hypothesized that children with mild or too severe bronchiolitis would not benefit for in-hospital $\mathrm{ACT}^{25}$. However, $\mathrm{ACT}$ referral is largely based on the subjectivity of the physician's prescription and on the physiotherapist's assessment. In our cohort, $63 \%$ of the infants received regular ACT during their hospital stay, without any clinically relevant significant difference between them, and those who did not. These results are consistent with the previous evidence on that topic since the studies that observed a benefit for ACT in children with acute viral bronchiolitis included children with a moderate profile $^{26}$. Clear and objective indications for ACT referral should be identified, as well as the profiles of the children that would eventually have a positive response to ACT. These two elements seem unavoidable to get 
rid of a one size fits all approach that seem inappropriate, as well as an approach only based on subjective features.

\section{Limitations}

This study has several limitations. Firstly, the retrospective design of this study may have induced bias. Also, the multivariate logistic regression model for LOFR almost reached statistical significance for all the factors that reached statistical significance in the univariate analyses. This suggests that our results could have been different with a larger sample size.

Secondly, some variables of interest may be absent or poorly reported in the medical records, particularly some features related to the infant's environment (parental smoking, familial history of atopy). Moreover, other variables of interest could be influenced by the pediatric services' usual practices, such as the prescriptions of bronchodilators. Also, socioeconomic factors were not retrieved in our analysis, because these variables were not reported in the medical records. Still, common socioeconomic criteria, namely the level of education, the occupation, the age, and the average parental income, have been shown to be associated with hospital referral and LOS, and could explain why $9 \%$ of the children in our cohort were admitted with only a mild bronchiolitis ${ }^{27,28}$.

Thirdly, the clinical severity scale proposed by the HAS has not been validated yet, and this study was the first to compare its results with LOS. Furthermore, the clinical severity was retrospectively rated, which is not the initial intended use of this scale and could have led to some inaccuracies. Nonetheless, some criteria from this scale (namely the assessment of respiratory distress) could be highly subjective from one caregiver to another. Since this sole criterion is sufficient to rate the clinical severity as "severe", the complete reliability of this tool should be investigated in the future. In our study, $52 \%$ of infants had a "severe" clinical severity on admission, mainly because of a RR "[?] 70/min or $<30 / \mathrm{min}$, or presence of apnea" or an altered general condition.

Lastly, the cut-off value used in the present study to describe adequate infant feeding was decided in the absence of a validated standard but could have influenced our results.

\section{Conclusion}

Maintaining adequate feeding during hospital stay is a key component of bronchiolitis care, the clinical severity on admission may be related to the length of recover adequate feeding (LOFR), ranging from none to significant. Other known factors such as oxygen therapy and the new clinical severity scale proposed by the latest French guidelines appeared to be related to the length of stay (LOS) in this work. On the other hand, bronchiolitis airway clearance technique (ACT) referral was not associated with neither LOFR nor LOS, suggesting that ACT use did not modify the course of these children's stay. Further robust work is needed to elucidate these questions.

\section{Acknowledgements}

Authors would like to thank the whole team of Le Havre for their support in this study.

\section{Informed Consent}

According to the French law, formal consent was not required for this type of study. 


\section{Conflicts of Interest}

The authors declare no conflicts of interest.

\section{References}

1. Ralston SL, Lieberthal AS, Meissner HC, Alverson BK, Baley JE, Gadomski AM, Johnson DW, Light MJ, Maraqa NF, Mendonca EA, et al. 2014. Clinical Practice Guideline: The Diagnosis, Management, and Prevention of Bronchiolitis. PEDIATRICS. 134(5):e1474-e1502.

2. Baraldi E, Lanari M, Manzoni P, Rossi GA, Vandini S, Rimini A, Romagnoli C, Colonna P, Biondi A, Biban P, et al. 2014. Inter-society consensus document on treatment and prevention of bronchiolitis in newborns and infants. Ital J Pediatr. 40:65.

3. Caffrey Osvald E, Clarke JR. 2016. NICE clinical guideline: bronchiolitis in children. Arch Dis Child Educ Pract Ed. 101(1):46-48.

4. Sannier N, Bocquet N, Timsit S, Cojocaru B, Wille C, Garel D, Boursiquot C, Cheron G. 2001. Evaluation du cout du premier episode de bronchiolite. Arch Pediatrie. 8(9):922-928.

5. Haute Autorite de Sante (H.A.S). 2019. Prise en charge du 1er episode de bronchiolite aigue chez le nourrisson de moins de 12 mois. Saint-Denis La Plaine.

6. Florin TA, Plint AC, Zorc JJ. 2017. Viral bronchiolitis. The Lancet. 389(10065):211-224.

7. Kirolos A, Manti S, Blacow R, Tse G, Wilson T, Lister M, Cunningham S, Campbell A, Nair H, Reeves RM, et al. 2019. A Systematic Review of Clinical Practice Guidelines for the Diagnosis and Management of Bronchiolitis. J Infect Dis.:S672-S679.

8. Corrard F, de La Rocque F, Martin E, Wollner C, Elbez A, Koskas M, Wollner A, Boucherat M, Cohen R. 2013. Food intake during the previous $24 \mathrm{~h}$ as a percentage of usual intake: a marker of hypoxia in infants with bronchiolitis: an observational, prospective, multicenter study. BMC Pediatr. 13(1):6.

9. Weisgerber MC, Lye PS, Nugent M, Li S-H, De Fouw K, Gedeit R, Simpson P, Gorelick MH. 2013. Relationship Between Caloric Intake and Length of Hospital Stay for Infants With Bronchiolitis. Hosp Pediatr. 3(1):24-30.

10. Schofield WN. 1985. Predicting basal metabolic rate, new standards and review of previous work. Hum Nutr Clin Nutr. 39 Suppl 1:5-41.

11. Joosten K, Embleton N, Yan W, Senterre T, Braegger C, Bronsky J, Cai W, Campoy C, Carnielli V, Darmaun D, et al. 2018. ESPGHAN/ESPEN/ESPR/CSPEN guidelines on pediatric parenteral nutrition: Energy. Clin Nutr. 37(6):2309-2314.

12. Bocquet A, Bresson JL, Briend A, Chouraqui JP, Darmaun D, Dupont C, Frelut ML, Ghisolfi J, Goulet O, Putet G, et al. 2003. Alimentation du nourrisson et de l'enfant en bas age. Realisation pratique. Arch Pediatrie. 10(1):76-81.

13. Gajdos V, Katsahian S, Beydon N, Abadie V, de Pontual L, Larrar S, Epaud R, Chevallier B, Bailleux S, Mollet-Boudjemline A, et al. 2010. Effectiveness of Chest Physiotherapy in Infants Hospitalized with Acute Bronchiolitis: A Multicenter, Randomized, Controlled Trial. PLoS Med. 7(9):1-12.

14. Che D, Nicolau J, Bergounioux J, Perez T, Bitar D. 2012. Bronchiolite aigue du nourrisson en France : bilan des cas hospitalises en 2009 et facteurs de letalite. Arch Pediatrie. 19(7):700-706. 
15. Ralston SL, Lieberthal AS, Meissner HC, Alverson BK, Baley JE, Gadomski AM, Johnson DW, Light MJ, Maraqa NF, Mendonca EA, et al. 2014. Clinical practice guideline: the diagnosis, management, and prevention of bronchiolitis. Pediatrics. 134(5):e1474-1502.

16. De Cosmi V, Mehta NM, Boccazzi A, Milani GP, Esposito S, Bedogni G, Agostoni C. 2017. Nutritional status, metabolic state and nutrient intake in children with bronchiolitis. Int J Food Sci Nutr. 68(3):378-383.

17. Li J, Li B, Qian J, Zhang J, Ren H, Ning B, Wang Y. 2020. Nutritional survey in critically ill children: a single center study in China. Transl Pediatr. 9(3):221-230.

18. Rollins NC, Bhandari N, Hajeebhoy N, Horton S, Lutter CK, Martines JC, Piwoz EG, Richter LM, Victora CG. 2016. Why invest, and what it will take to improve breastfeeding practices? The Lancet. 387(10017):491-504.

19. Victora CG, Bahl R, Barros AJD, Franca GVA, Horton S, Krasevec J, Murch S, Sankar MJ, Walker N, Rollins NC. 2016. Breastfeeding in the 21st century: epidemiology, mechanisms, and lifelong effect. The Lancet. 387(10017):475-490.

20. Black RE, Victora CG, Walker SP, Bhutta ZA, Christian P, de Onis M, Ezzati M, Grantham-McGregor S, Katz J, Martorell R, Uauy R. 2013. Maternal and child undernutrition and overweight in low-income and middle-income countries. The Lancet. 382(9890):427-451.

21. Unger S, Cunningham S. 2008. Effect of Oxygen Supplementation on Length of Stay for Infants Hospitalized With Acute Viral Bronchiolitis. PEDIATRICS. 121(3):470-475.

22. Fauroux B, Hascoet J-M, Jarreau P-H, Magny J-F, Roze J-C, Saliba E, Schwarzinger M. 2020. Risk factors for bronchiolitis hospitalization in infants: A French nationwide retrospective cohort study over four consecutive seasons (2009-2013).Katz M, editor. PLOS ONE. 15(3):e0229766.

23. Shashidhar A, Suman Rao P, Joe J. 2016. Downes Score vs Silverman Anderson Score for Assessment of Respiratory Distress in Preterm Newborns. Pediatr Oncall. 13(3):66-68.

24. Gehri M, Krahenbuhl J, Landry J, Gervaix A. 2005. L'enfant dyspneique. Rev Medicale Suisse. 1(7):486-90.

25. Postiaux G, Zwaenepoel B, Louis J. 2013. Chest Physical Therapy in Acute Viral Bronchiolitis: An Updated Review. Respir Care. 58(9):1541-1545.

26. Conesa-Segura E, Reyes-Dominguez SB, Rios-Diaz J, Ruiz-Pacheco MA, Palazon-Carpe C, SanchezSolis M. 2018. Prolonged slow expiration technique improves recovery from acute bronchiolitis in infants: FIBARRIX randomized controlled trial. Clin Rehabil.:504-515.

27. Jones LL, Hashim A, McKeever T, Cook DG, Britton J, Leonardi-Bee J. 2011. Parental and household smoking and the increased risk of bronchitis, bronchiolitis and other lower respiratory infections in infancy: systematic review and meta-analysis. Respir Res. 12(1):1-11.

28. Corneli HM, Zorc JJ, Holubkov R, Bregstein JS, Brown KM, Mahajan P, Kuppermann N. 2012. Bronchiolitis: Clinical Characteristics Associated With Hospitalization and Length of Stay. Pediatr Emerg Care. 28(2):99-103. 


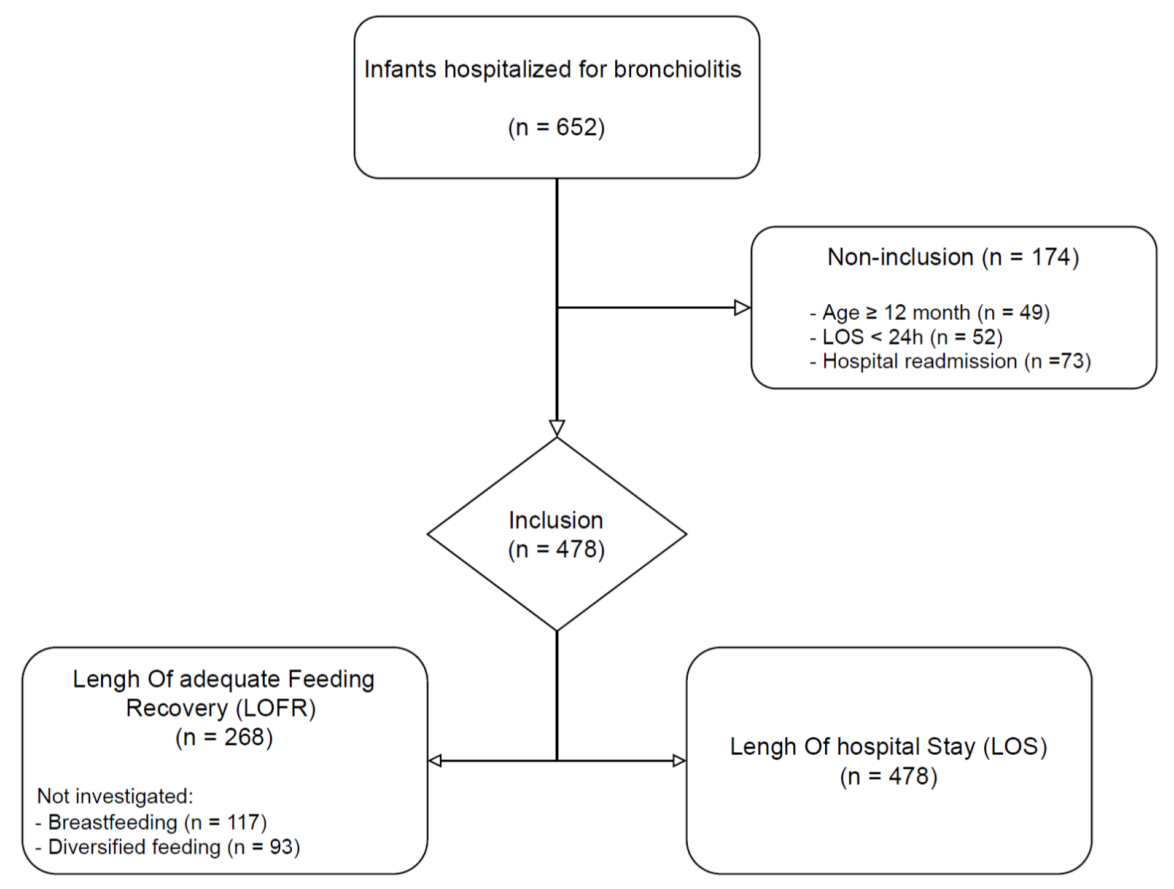

\section{Hosted file}

Table 1.docx available at https://authorea.com/users/461305/articles/557024-factorsassociated-with-length-to-recover-adequate-nutrition-and-length-of-stay-in-childrenhospitalized-for-bronchiolitis-a-retrospective-study

\section{Hosted file}

Table 2.docx available at https://authorea.com/users/461305/articles/557024-factorsassociated-with-length-to-recover-adequate-nutrition-and-length-of-stay-in-childrenhospitalized-for-bronchiolitis-a-retrospective-study

\section{Hosted file}

Table 3.docx available at https://authorea.com/users/461305/articles/557024-factorsassociated-with-length-to-recover-adequate-nutrition-and-length-of-stay-in-childrenhospitalized-for-bronchiolitis-a-retrospective-study 